\title{
Study on the Relationship between Public Opinion and Democracy and Rule of Law in the Context of Internet
}

\author{
Xinxin Zhou \\ Shihezi University institute of Marxism, Xinjiang, Shihezi, 832003
}

Keywords: Network Public Opinion; Democratic Politics; Legalization

\begin{abstract}
With the development of society, network technology is constantly advancing with the times, people in the Internet environment can freely express their own ideas, pay attention to Chinese political dynamics, this paper through the analysis of Internet-based citizens to participate in the network of democratic politics The change of the construction of democratic politics in our country, and then understand the relationship between the network public opinion and the democratic rule of law, and put forward the corresponding countermeasures for the limitation of the network public opinion.
\end{abstract}

\section{Introduction}

The rapid development of Internet technology has made the participation of citizens' democratic politics play a better platform and a more relaxed political atmosphere. Citizens have a better channel in obtaining democratic political information, expressing their own interests and participating in democratic political decision-making process and the way. The current public opinion in the process of promoting democratic politics to the domestic political environment and social stability have brought some risks and crises, timely research and grasp the trend of public opinion, to build a harmonious and stable network of public opinion environment, to promote the healthy development of democracy, For the construction of socialist political civilization, to achieve social stability and harmony has great theoretical and practical significance.

\section{The Characteristics of Civil Political Participation in the Internet Age}

At present, because each netizen can through the Internet to understand the information disclosed by the government, and for the progress of government departments to carry out management and supervision, and truly exercise their own citizens have the right to publish recommendations to achieve the domestic upper and lower levels of mutual ventilation, Mutual exchange of mutual effect, to stimulate the enthusiasm of citizens to participate in politics, showing the network of directness and objectivity, specifically the following aspects of the characteristics.

Network platform with efficient and open features, and now users can publish their own information on the network, and then to achieve the integration of network information, such as the current two sessions each year, a lot of news information sites, portals will set up a special hotspot introduction and discussion, This includes a lot of public interest issues, such as people's livelihood, ecology, health care, housing, pension and other social problems, but also related to the hot topic of clean anti-corruption, so the network issues have a wide range of participatory characteristics.

Because of the timeliness, interaction and connection characteristics of the Internet, it will make the influence of different cultural thoughts such as grassroots, various occupations and various identities in the Internet users, so that the Internet has the center of diversified ideological exchange Will make a variety of information transmission speed amplification, leading to disrupt the civil life of the normal order of the vicious incident.

Network communication to make up for the limitations of traditional media, you can make a variety of ideas of mutual expansion and integration of the gradual realization of integration, and then the formation of public opinion, it does not make all levels of citizens can have a certain right 
to speak, and through the Internet platform To express their views and opinions, and to advise and advise on the work of government departments.

\section{New Changes of Chinese Democratic Political Construction in the Network Era}

In the past, public opinion, traditional media and democracy and the rule of law there is an imbalance between the state, the emergence of the Internet to the construction of democratic politics has brought new opportunities, the past people used to the traditional political participation model, but now the network The development has led to the broad pursuit of democracy and the influence of people's political consciousness, thus affecting the government's related behavior.

At present, the promotion of democracy and the rule of law in our country, the first is to enhance the public awareness of democracy, but in the past, the people rarely participate in political life, but the network for our democratic political construction provides a new way of propaganda, Therefore, we need to awaken the consciousness of the masses of the people so that people can participate in the construction of democratic politics, and then promote the process of democratic political construction in China, and let this awareness can be internalized to participate in the construction of democracy and the rule of law in China, and provide power for the construction of democracy and rule of law source.

With the continuous improvement of civic awareness, the people will seize every opportunity to express their views, the correct and reasonable exercise of their rights is what the people expect, but also for the construction of democratic rule of law requirements are more and more urgent, for this situation, Our country is also in an orderly manner to carry out this work. First of all, let the public can take the initiative to participate in political participation, the correct implementation of the people-centered strategy, the Internet has become an important platform for the public to participate in democracy and the rule of law, on the one hand, Internet users in the Internet to show great politics Enthusiasm, but also for the citizens to participate in politics to provide a lot of opportunities; the other hand, the Internet integration of various views, breaking the closed political situation, the participation of democracy and the rule of law there will be a bottom-up change , When the views of the public gathered into a strong network of public opinion, you can promote the formation of the upper decision-making, and thus affect the political decision-making process and decision-making content. Therefore, it can be said that this important channel of the Internet for the realization of the rapid development of democracy and the rule of law in China has a very important practical significance, many local people have noticed the importance of network participation in the construction of democracy and the rule of law, so began in the network pilot, And then in the political life can be used.

Internet public opinion is through the network platform to play out of public opinion, there is a great deal of compatibility, Internet users can always express their views and timely release and network, and condensed into a network of public opinion and then by the traditional media attention, and become a society Public events, to meet the requirements of network democracy.

\section{The Public Context of the Internet Promoting the Construction of National Rule of Law}

In the context of the Internet, the network technology is recognized by the broad masses of the people and put into real practical operation, constantly enrich the people's life, but also in the construction of the rule of law has played a very important role.

According to research data show that Chinese current Internet users have reached 721 million people, especially young Internet users in particular. Therefore, the Internet can be used as a citizen to exercise power, express ideas, one of the ways to fulfill their obligations, the application of the Internet will be able to make better decisions, so that people's quality of life has been further enhanced and safeguarded.

As the country's major policies and people's lives are closely related, it makes all levels of the people have the desire to participate in politics, and now the rapid development of the network, so that people can get a lot of information resources for the first time, you can express their own 
wishes The Such as the public events in recent years, these major things in the country caused a great response to the Internet users themselves broaden their horizons, but also to the national government departments have a new understanding of the relevant issues can be promptly resolved, so that the majority of citizens real consciousness To participate in the influence of national affairs, inspired the enthusiasm of the people.

With the continuous increase of Chinese economic and political system reform, deep-seated reform has become inevitable, in the process of reform will inevitably appear some new contradictions and problems in the network, people can not be restricted to express their own Of the demands, if this time to the widespread spread of the demands, will be able to cause the concerns of the party committee and government, it will promptly resolve contradictions and problems, which can increase the resolution of the problem, ease social contradictions, for now, a lot of places The government has been actively contact with new things, into the network, such as the Guangdong Provincial Party Secretary Wang Yang on the initiative to meet friends to understand public opinion, some local cities and counties through the network to answer friends concerned about social issues, and so these are social problems quickly The solution provides a good channel and also reduces the degree of contradiction.

People can through the network to expose some corruption phenomenon, at the same time for the government information disclosure, democratic decision-making, sunshine and other aspects of the role of supervision. Such as the black brick kiln incident related to the removal of government officials, to the astronomical cigarettes have also been found, and then to examine the door incident, and then show the power of network technology, the use of public opinion, the characteristics of supervision of various government officials, to achieve supervision Object and the breadth of the object being monitored.

\section{The Adverse Impact of Public Opinion on the Construction of Democracy and the Rule of Law}

Network as a new communication channel, it has a timely, wide coverage of information, the advantages of strong participation, making it an important place for Internet users to express ideas and demands, but because there is no corresponding legal system constraints will make public opinion Are into the unreasonable, illegal point, resulting in a large social instability phenomenon, such as in the recent public events, the Chinese Internet users to show the irrational characteristics of the original is a mutual respect for the freedom of the network The platform was so extreme thinking around, making the network has become a malicious abuse of the place. Therefore, we need to understand the network structure of Internet users and understand their characteristics, hobbies, ideological level and moral compliance of the differences, the only way to be able to analyze the breadth of the network of public opinion.

Because the participation in the network to communicate, is the need for more resources, so although the network can make the majority of people express their own ideas and views, but the use of the Internet in general, the proportion of elite people to participate in higher than vulnerable groups, The conditions of the restrictions make the network public opinion in a short time can not play its role as the mainstream public opinion, only part of the group to use the network to express their own interests of the platform, most vulnerable groups can not express and listen, so that some people can not participate Political democracy and the rule of law in the process of construction, and some network point of view can not distinguish between personal ideas or social ideas.

The most important feature of the network is open, then it means that all Internet users are free to express their aspirations and aspirations, which inevitably bring some emotional things in the inside, and in real life, the public express their own Point of view at the same time, will be subject to political culture and other constraints. This makes the network express their views, will each other between the imitation of each other, the basic sense of moral and sense of responsibility will disappear, for some Internet users that unreasonable people and things will be the so-called moral justice repression and lash, which reflects the Characteristics of Irregularity in Network.

On the Internet, some people will be aware of the controversial or social focus of the formation 
of their own groups of understanding, when this subjective understanding of the majority or dominant state, it will be proactive to express, on the contrary some of the number of public found When you are in a minority or at a disadvantage, choose to stay cautious and silent in order to avoid the pressure of being isolated from the social environment. When these strong views are displayed on the web, they are slowly gathered by some people This part of the power and then form a group of events, then it will form a group of events, such as the most cattle nail household events, it caused the atmosphere of public opinion affected the relevant government departments of law enforcement, and thus affect the public interest.

\section{Countermeasures for the Relationship between the Public Opinion and Democracy and the Rule of Law on the Network}

In the face of the flood of the network of public opinion, only to establish and improve the relevant network management laws and regulations, improve the network public opinion response system, establish a correct public opinion, in order to allow users to participate in an orderly space inside the process of democracy and rule of law.

We need to fully understand the characteristics of the network of public opinion, timely through the network to reflect the social situation and public opinion, and the information back to the party committee and government to promote the government's scientific decision-making, so that the work can be carried out efficiently.

We should make full use of the network platform, and actively listen to and feedback netizens' opinions and ideas, the party committee and government important decision-making and livelihood measures, released through the network, and collect relevant policy advice, the use of advanced network technology, screening valuable network Social opinion and public opinion.

We should pay attention to increase the intensity of network personnel training, the establishment of a strong political stance, professional level and network technology and excellent team of talent, regularly browse the major sites, and through the network public opinion analysis to identify social hot and difficult problems, and This information is summarized, the formation of valuable information, feedback to the party committee and government, for the party committee and government decision-making help, but also can solve the concerns of the masses, but also to strengthen the network civilization and social morality propaganda, and actively around the masses Concerned about the hot spots and focus issues to post, take the initiative to guide citizens to spread health information, to resist bad and harmful information, to maintain the credibility of the party committee and government, to contribute to social harmony.

In short, for the advent of the Internet age, we can not escape, we should make better use of the network platform for the construction of democracy and the rule of law, in the network environment, the people get the right to speak freely, mastered a certain information release and acceptance Rights, and can actively participate in the use of information into the network, a good, orderly network of public space, which for people to participate in political rights has a very important role in the supervision of public power will be more effective, Only to establish a scientific and useful public areas in order to form a good network of public opinion and the government benign interaction platform, we have good expectations and hope, but we are concerned about the network when the major role of the same do not ignore the network Negative role, and guide the Internet to the benign role of democratic participation.

\section{References}

[1] Zhan John John Srezek. Deliberative Democracy and Its Transcendence: A Perspective of Freedom and Criticism [M]. Ding Kaijie, Beijing: Central Compilation and Translation Press, 2006: 157.

[2] Liu Zehua. China's royalism [M]. Shanghai: Shanghai People's Publishing House, 2007: 164.

[3] National judicial examination counseling book editorial board. 2009 national judicial 
examination laws and regulations compilation [M]. Beijing: China University of Political Science and Law Press, 2009: 615.

[4] Zhou Jun. Internet era of public opinion and democracy and the rule of law [J]. Journal of Xinyang Agricultural College .2011,21 (1): 52-55

[5] Chen Jun. Briefly on the network of public opinion and civic democratic participation [J]. Legal and social .2009,11: 227-229

[6] The risk and strategy of civil society's political participation in the new media environment [J]. Journal of Economic Research, 2010,24 (6): 198-199

[7] Cao Zhongan, Zhu Xia. The Inner Value and Externality of "Network Public Opinion" in the View of Rule of Law [J] .Chinese Journal of Politics and Politics [J]. Chongqing and the World .2011,28 (2): 28-30 